\title{
Intraocular Pressure Spikes following Neodymium-doped Yttrium Aluminum Garnet Laser Capsulotomy: Current Prevalence and Management in Israel
}

\section{Asaf Achiron}

\begin{abstract}
Aim: The current treatment for posterior capsular opacification (PCO), neodymium-doped yttrium aluminum garnet (Nd:YAG) laser capsulotomy, may lead to increased intraocular pressure (IOP). Our aim was to survey routines in the management of IOP spikes and to identify the rate of IOP spikes following prophylactic apraclonidine treatment.
\end{abstract}

Materials and methods: A survey questionnaire among ophthalmologists and a retrospective registry review was used. Patients were administered apraclonidine $0.5 \%$ prior to capsulotomy. The IOP was measured before and 1 hour postprocedure.

Results: A total of $71 \%$ of responders $(n=45)$ routinely prescribe topical IOP-lowering medication and $82 \%$ routinely measure IOP before or after capsulotomy. The registry analysis included 87 eyes of 75 patients. Mean IOP decreased by $0.9 \pm$ $3.3 \mathrm{~mm} \mathrm{Hg}$ ( $p=0.01$, range: -6 to 10$)$ following capsulotomy. No patient reached IOP values above $21 \mathrm{~mm} \mathrm{Hg}$ following the procedure, with 3.4 and $1.1 \%$ of patients demonstrating an IOP elevation of more than 3 and $5 \mathrm{~mm} \mathrm{Hg}$ respectively. No association was found between number of laser shots, mean laser power, or comorbid conditions, such as diabetes, hypertension, or glaucoma status with posttreatment IOP.

Conclusion: Most ophthalmologists surveyed routinely prescribe prophylactic IOP-lowering medication and measure IOP before or after capsulotomy. Mean IOP remained clinically stable following capsulotomy with prophylactic apraclonidine instillation, and no patient reached IOP values above $21 \mathrm{~mm}$ $\mathrm{Hg}$. Differences in laser delivery or comorbid conditions were not associated with posttreatment IOP. Considering that no patient demonstrated a clinically significant IOP spike following prophylactic apraclonidine instillation, perhaps routine measurement of IOP following primary Nd:YAG laser may be reserved for high-risk patients only.

Clinical significance: In this work, we showed the prophylactic effect of apraclonidine $0.5 \%$ and suggest that measuring IOP after the procedure is necessary only in certain high-risk cases, possibly helping to reduce workload and patient waiting time and improving quality of service.

Keywords: Apraclonidine, Cataract surgery, Intraocular pressure, Neodymium-doped yttrium aluminum garnet laser capsulotomy, Posterior capsular opacification.

\section{Resident}

Department of Ophthalmology, Edith Wolfson Medical Center Holon, Israel

Corresponding Author: Asaf Achiron, Resident, Department of Ophthalmology, Edith Wolfson Medical Center, Holon, Israel Phone:+97235028706, e-mail: achironasaf@gmail.com
How to cite this article: Achiron A. Intraocular Pressure Spikes following Neodymium-doped Yttrium Aluminum Garnet Laser Capsulotomy: Current Prevalence and Management in Israel. J Curr Glaucoma Pract 2017;11(2):63-66.

\section{Source of support: Nil}

Conflict of interest: None

\section{INTRODUCTION}

Posterior capsular opacification is the most common postoperative complication of cataract surgery with a cumulative 5-year incidence of $11.9 \%{ }^{1}$ The treatment of choice for PCO is short pulsed Nd:YAG laser applied to the posterior capsule in order to create an opening in the visual axis. Although considered safe, it may result in retinal detachment, lens subluxation, and lens pitting. The most common complication is a transient increase in IOP, which may occur in 15 to $36 \%$ of patients who receive no prophylactic treatment. ${ }^{2-6}$ This IOP spike may lead to additional injury in eyes with advanced glaucomatous optic nerve damage. ${ }^{2}$

Several controlled studies from recent decades have investigated IOP-lowering agents and demonstrated successful control of IOP. ${ }^{3-12}$ Routine practice and outcomes in real-life settings, however, have not been as thoroughly explored. Apraclonidine $0.5 \%$ is a common choice as a prophylactic treatment prior to laser capsulotomy. ${ }^{8,13}$ Reported rates of IOP spikes above $5 \mathrm{~mm} \mathrm{Hg}$ following prophylactic apraclonidine $0.5 \%$ and capsulotomy vary between 2 and $8.5 \% .^{2,5,11,12}$

The purpose of this study was to survey routines in the management of post Nd:YAG laser capsulotomy IOP spike in Israel and to identify the rate of postprimary Nd:YAG laser capsulotomy IOP spikes following one drop of prophylactic apraclonidine $0.5 \%$ treatment.

\section{MATERIALS AND METHODS}

\section{Survey Questionnaire}

Questionnaires were sent via e-mail to ophthalmologists registered at the Tel Aviv University Continuous Medical Education (CME) network. Ophthalmologists were asked to complete a 14-question internet-based survey 
regarding their IOP management routine, following capsulotomy (https://goo.gl/forms/87ZCQMO0189sFqow2).

\section{Retrospective Registry Review}

Charts of patients who had undergone primary Nd:YAG laser capsulotomy were reviewed. Demographic data, time since cataract surgery, and relevant medical diagnoses were extracted. Patients who had previously undergone Nd:YAG laser capsulotomy in the same eye were excluded. All subjects were treated with one drop of apraclonidine $0.5 \%$ prior to the procedure and another physician measured IOP 1 hour posttreatment using Goldmann applanation tonometry. Change in IOP was calculated for each patient as the difference between preand posttreatment IOPs.

\section{Statistical Analysis}

Descriptive data and the proportion of patients who had IOP $>21 \mathrm{~mm} \mathrm{Hg}$ were calculated using Statistical Package for the Social Sciences version 17 By IBM Inc. Correlation analysis between $\triangle \mathrm{IOP}$ (IOP before and after treatment) and visual acuity was conducted in addition to three logistic regression analyses. Successful outcomes following treatment were defined as those having an IOP $<21$ $\mathrm{mm} \mathrm{Hg}$, absolute change in $\mathrm{IOP} \leq 3$ and $\leq 5 \mathrm{~mm} \mathrm{Hg}$, and IOP change $<20 \%$. This study was approved by the Edith Wolfson Institutional Review Board Committee.

\section{RESULTS}

\section{Online Survey}

Total response rate for the survey questionnaire was $54 \%$ (45 of 83), responses were received from two-thirds of all certified ophthalmology teaching departments in Israel $(13 / 19)$. The mean age of responders was $36.6 \pm 8.4$ years, $65.9 \%$ were male, $75.0 \%$ were residents, and the median of experience in ophthalmology practice was 3.0 years. The IOP measurement was routinely performed before and/or after the procedure by $81.8 \%$ of responders $(68.2 \%$ only before, $68.2 \%$ only after); $18.2 \%$ do not measure IOP at all and 54.5\% responded that they measured IOP twice (before and after capsulotomy).

Topical medication to lower IOP before and/or after the capsulotomy was prescribed by $74.4 \%$ of responders (52.3\% only before, $38.1 \%$ only after); $25.6 \%$ do not initiate any prophylactic IOP reduction treatment and 16.3\% responded that they routinely prescribe topical medication twice (before and after capsulotomy).

Of responders who routinely prescribe topical IOPlowering medication, $81.8 \%$ also measure, at least once, the IOP (54.5\% before and 59.1\% after capsulotomy). Only $54.5 \%$ of responders who do not prescribe any topical antiglaucoma therapy also measure IOP at least once. Average time from preventive IOP treatment to capsulotomy was $15.9 \pm 14.6$ minutes (median 7.5 minutes).

\section{Retrospective Registry Review}

A total of 87 eyes of 75 patients (62.1\% female) were included in the study. One eye of one patient was excluded because the patient had undergone previous Nd:YAG laser capsulotomy in that eye. The mean age was $75.6 \pm 9.3$ years; $29.9 \%$ had diabetes, $64.4 \%$ had systemic hypertension, and $14.9 \%$ had glaucoma $(n=13$, all were treated). Mean time from cataract surgery was $32.0 \pm 22.4$ months. The mean number of laser shots was $21.8 \pm 12.2$ and mean laser power was $3.1 \pm 0.5 \mathrm{~mJ}$.

Following capsulotomy and apraclonidine prophylactic treatment, average IOP remained clinically stable $(14.0 \pm 2.6$ to $13.1 \pm 2.9 \mathrm{~mm} \mathrm{Hg}$, IOP change: $-0.9 \pm 3.3 \mathrm{~mm} \mathrm{Hg}$, range: -6 to $10 ; \mathrm{p}=0.01)$. Three cases $(3.4 \%)$ experienced an increase in IOP of more than $3 \mathrm{~mm} \mathrm{Hg}$ and only one case $(1.1 \%)$ more than $5 \mathrm{~mm} \mathrm{Hg}$.

Subgroup analysis revealed that glaucoma patients had a higher IOP prior to treatment compared with nonglaucoma patients $(15.6 \pm 3.9$ vs $13.6 \pm 2.2 \mathrm{~mm} \mathrm{Hg}$ respectively, $\mathrm{p}=0.01$ ). There was no significant postreatment difference in the mean IOP (13.1 vs $13.0 \mathrm{~mm} \mathrm{Hg}$, $\mathrm{p}=0.9)$. The absolute change in IOP, however, was larger in the glaucoma patients group ( $\triangle \mathrm{IOP}:-2.6 \pm 4.0$ vs -0.57 $\pm 3.0 \mathrm{~mm} \mathrm{Hg}, \mathrm{p}=0.03)$. None of the eyes demonstrated a clinically significant rise in IOP (Graph 1).

No association was found between number of laser shots, mean laser power, or absolute amount of laser delivered (number of shots multiplied by the power) to either posttreatment IOP or IOP change.

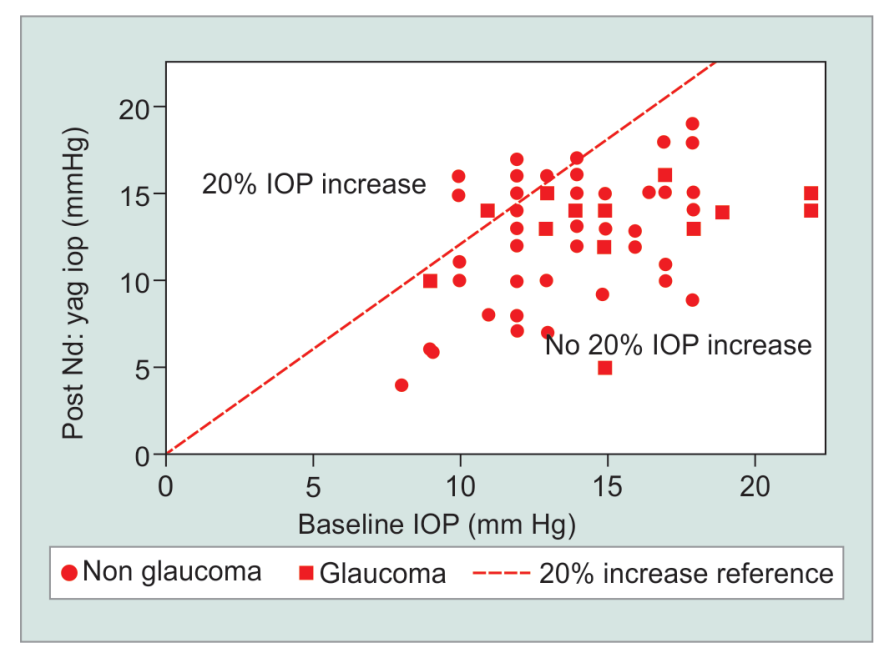

Graph 1: Scatter plot of post Nd:YAG laser capsulotomy IOP vs baseline IOP. Squares represent eyes of patients with glaucoma and circles represent eyes of patients without glaucoma. The dashed reference line represents an increase of $20 \%$ or more from baseline IOP. None of the eyes demonstrated a clinically significant rise in IOP over $21 \mathrm{~mm} \mathrm{Hg}$ 


\section{DISCUSSION}

Acute IOP elevation following capsulotomy is common among patients who do not receive prophylactic treatment and may occur in 15 to $36 \%$ of cases..$^{2,4-7,9}$ When prophylactic treatment is prescribed, however, an IOP spike above $5 \mathrm{~mm} \mathrm{Hg}$ is seen in only 2 to $8.5 \%$ of cases. ${ }^{2}$ The increased IOP may be caused by reduced aqueous humor outflow facility due to capsular debris, cells (erythrocytes, lymphocytes, and macrophages), fibrin, pigment, and other materials that may clog the trabecular meshwork. Shock waves created by the laser may also damage the trabecular meshwork, causing clogs.

In our study, patients received prophylactic apraclonidine and $1.1 \%$ of cases ( 1 of 87 ) experienced an IOP increase above five, with no patients reaching IOP values above $21 \mathrm{~mm} \mathrm{Hg}$. These results are in line with those of other researchers when using prophylactic IOP-lowering medication. Holweger and Marefat ${ }^{8}$ reported that $1 \%$ of 101 patients had IOP spikes over $5 \mathrm{~mm} \mathrm{Hg}$ following their capsulotomies. Barnes et $\mathrm{al}^{2}$ reported a $2 \%$ rate among 47 patients treated with either acetazolamide or apraclonidine. Unal et $\mathrm{al}^{11}$ examined 115 patients and reported a stable IOP following apraclonidine and capsulotomy (from 16.1 to $15 \mathrm{~mm} \mathrm{Hg}$ ) and a relatively high rate of IOP spikes $>5 \mathrm{~mm} \mathrm{Hg}$ seen in $8.6 \%$ (5/58) of their patients.

Apraclonidine $0.5 \%$ was effective in our glaucoma subgroup, with a mean IOP reduction of $2.6 \pm 4.0 \mathrm{~mm} \mathrm{Hg}$ (95\% confidence interval: -2.0 to -0.95 ). Moreover, glaucoma status was not a contributor for the risk of an IOP spike in our cohort. Barnes et $\mathrm{al}^{2}$ also reached a similar conclusion, showing that only $4 \%(1 / 23)$ of glaucoma patients who received apraclonidine prior to their capsulotomies experienced an IOP rise greater than $5 \mathrm{~mm} \mathrm{Hg}$.

We did not find any of the investigated laser parameters to have a significant clinical effect on IOP change or posttreatment values. This is in contrast to a report by Ari et $\mathrm{al}_{1}^{14}$ who demonstrated that higher laser power is associated with a greater IOP spike.

One possible implication arising from these results is the possibility to forego the 1 hour postlaser IOP measurement. Long waiting times are a major source of patient dissatisfaction and may adversely affect clinical outcomes and patient compliance with treatment regimens; waiting times have been found to be an important factor in rating service quality and overall patient satisfaction. ${ }^{15}$ It is therefore important to critically assess every decision affecting patient waiting times in the clinic. Given the low rates of IOP spikes in patients treated with IOP-lowering medication, reported here and in other studies, it might be reasonable to consider this avenue of action in low-risk patients.

Our survey included responses on the management of IOP spike following capsulotomy from two-thirds of all certified teaching departments in Israel (13/19). By targeting the university CME network contacts list, we had achieved high response rate from residents. As residents perform capsulotomy from an early stage in their residency, the survey results encompassed current practice and were exposed to limited recall biases.

To conclude, most ophthalmologists surveyed routinely prescribe prophylactic IOP-lowering medication and measure IOP before or after capsulotomy. Mean IOP remained clinically stable following capsulotomy with prophylactic apraclonidine instillation. Increase in IOP above $5 \mathrm{~mm} \mathrm{Hg}$ was observed in $1.1 \%$ of cases (1/87) and no patients reached IOP values above $21 \mathrm{~mm} \mathrm{Hg}$ following the procedure. Differences in laser delivery or comorbid conditions were not associated with posttreatment IOP.

\section{CLINICAL SIGNIFICANCE}

In this work, we showed the prophylactic effect of apraclonidine $0.5 \%$ and suggest that measuring IOP after the procedure is necessary only in certain high-risk cases, possibly helping to reduce workload and patient waiting time and improving quality of service.

\section{REFERENCES}

1. Sundelin K, Almarzouki N, Soltanpour Y, Petersen A, Zetterberg M. Five-year incidence of Nd:YAG laser capsulotomy and association with in vitro proliferation of lens epithelial cells from individual specimens: a case control study. BMC Ophthalmol 2014 Oct;14:116.

2. Barnes EA, Murdoch IE, Subramaniam S, Cahill A, Kehoe B, Behrend M. Neodymium:yttrium-aluminum-garnet capsulotomy and intraocular pressure in pseudophakic patients with glaucoma. Ophthalmology 2004 Jul;111(7):1393-1397.

3. Ge J, Wand M, Chiang R, Paranhos A, Shields MB. Long-term effect of Nd:YAG laser posterior capsulotomy on intraocular pressure. Arch Ophthalmol 2000 Oct;118(10):1334-1337.

4. Ladas ID, Baltatzis S, Panagiotidis D, Zafirakis P, Kokolakis SN, Theodossiadis GP. Topical 2.0\% dorzolamide vs oral acetazolamide for prevention of intraocular pressure rise after neodymium:YAG laser posterior capsulotomy. Arch Ophthalmol 1997 Oct;115(10):1241-1244.

5. Minello AA, Prata Junior JA, Mello PA. Efficacy of topic ocular hipotensive agents after posterior capsulotomy. Arq Bras Oftalmol 2008 Sep-Oct;71(5):706-710.

6. Sesar A, Petric I, Sesar I, Lacmnovic-Loncar V, Jurisi D, Tomi Z, Mandi Z. Intraocular pressure after ND: YAG laser capsulotomy in pseudophakic patients with glaucoma. Acta Med Croatica 2006 Jan;60(2):109-112.

7. Chen TC, Ang RT, Grosskreutz CL, Pasquale LR, Fan JT. Brimonidine $0.2 \%$ versus apraclonidine $0.5 \%$ for prevention of intraocular pressure elevations after anterior segment laser surgery. Ophthalmology 2001 Jun;108(6):1033-1038.

8. Holweger RR, Marefat B. Intraocular pressure change after neodymium:YAG capsulotomy. J Cataract Refract Surg 1997 Jan-Feb;23(1):115-121.

9. Rakofsky S, Koch DD, Faulkner JD, Terry SA, Mandell AI, Gross RL, Kelley EP, Iacono TL, Lue J. Levobunolol 0.5\% and 
timolol $0.5 \%$ to prevent intraocular pressure elevation after neodymium:YAG laser posterior capsulotomy. J Cataract Refract Surg 1997 Sep;23(7):1075-1080.

10. Seong GJ, Lee YG, Lee JH, Lim SJ, Lee SC, Hong YJ, Kwon OW, Kim HB. Effect of $0.2 \%$ brimonidine in preventing intraocular pressure elevation after Nd:YAG laser posterior capsulotomy. Ophthalmic Surg Lasers 2000 Jul-Aug;31(4):308-314.

11. Unal M, Yucel I, Akar Y. Brinzolamide $1 \%$ versus apraclonidine $0.5 \%$ to prevent intraocular pressure elevation after neodymium:YAG laser posterior capsulotomy. J Cataract Refract Surg 2006 Sep;32(9):1499-1502.

12. Rosenberg LF, Krupin T, Ruderman J, McDaniel DL, Siegfried C, Karalekas DP, Grewal RK, Gieser DK, Williams R. Apraclonidine and anterior segment laser surgery. Comparison of $0.5 \%$ versus $1.0 \%$ apraclonidine for prevention of postoperative intraocular pressure rise. Ophthalmology 1995 Sep;102(9):1312-1318.

13. Chen TC. Brimonidine $0.15 \%$ versus apraclonidine $0.5 \%$ for prevention of intraocular pressure elevation after anterior segment laser surgery. J Cataract Refract Surg 2005 Sep;31(9):1707-1712.

14. Ari S, Cingu AK, Sahin A, Cinar Y, Caca I. The effects of Nd:YAG laser posterior capsulotomy on macular thickness, intraocular pressure, and visual acuity. Ophthalmic Surg Lasers Imaging 2012 Sep-Oct;43(5):395-400.

15. McMullen M, Netland PA. Wait time as a driver of overall patient satisfaction in an ophthalmology clinic. Clin Ophthalmol 2013 Aug;7:1655-1660. 